\title{
Revisión \\ Una mirada al EJERCICIO de la caricatura política \\ en la provincia de El Oro
}

\author{
Anabel Moreno \\ amoreno_est国utmachala.edu.ec \\ Fernanda Tusa \\ ftusa国utmachala.edu.ec
}

Recibido: 15 de julio de 2020 | Aceptado: 28 de julio de 2020

D0I: https://doi.org/0.18272/pd.v4i1.1880

Referencia de este artículo:

Moreno, A. y Tusa, F. (2020). Una mirada al ejercicio de la caricatura política en la provincia de El Oro. \#PerDebate, volumen 4 (pp. 46-67). Quito: USFQ Press.

Anabel Moreno es Licenciada en Comunicación por la Universi-

dad Técnica de Machala. Trabaja en emprendimientos digitales y

tiene experiencia en reportería en medios de prensa locales.

Fernanda Tusa es Doctora en Comunicación. Máster en Comunicación y Educación. Máster en Medios en Red y Ciencias de la Web. Docente de la Facultad de Ciencias Sociales de la Universidad Técnica de Machala, provincia de El Oro. 


\title{
Resumen
}

Esta investigación analiza el ejercicio periodístico de la caricatura política, focalizando el estudio en la provincia de El Oro. La metodología cualitativa aplicó la técnica de la entrevista a caricaturistas y periodistas. Como resultado destaca el criterio de que los caricaturistas orenses ejercen un oficio empírico y, aun sin formación previa, consideran que la caricatura política debe ser permitida siempre y cuando respete la honra ajena, con el fin de evitar un humor absurdo y abusivo.

\section{Palabras clave}

caricatura política, caricaturista, libertad de expresión, prensa escrita, medio de comunicación, periodista local

\section{A look at the exercise of political caricature in the province of El Oro}

\begin{abstract}
This research analyzes the journalistic exercise of political cartoons, focusing the study on the province of El Oro. The qualitative methodology applied the interview technique to cartoonists and journalists. As a result, the criterion that Orense cartoonists exercise an empirical profession stands out and, even without prior training, they consider that political caricature should be allowed as long as it respects the honor of others, in order to avoid an absurd and abusive humor.
\end{abstract}

\section{Keywords}

political cartoon, cartoonist, freedom of speech, written press, mass media, local journalist 


\section{Introducción}

La caricatura periodística es un retrato dibujado humorísticamente con distorsiones, con exageraciones de las partes físicas más notables de los personajes que son dibujados, son imágenes que expresan opiniones sobre los temas de relevancia para la sociedad, asuntos que generan debate en la colectividad y, así, los lectores reflexionan sobre lo que está pasando en su contexto. De hecho, la caricatura es un mensaje humorístico sobre un tema importante, es la parte graciosa de una noticia. Las personas que realizan caricaturas buscan dar a conocer sus opiniones y críticas sobre las acciones, funciones y decisiones de los personajes protagonistas de la esfera pública. Ya en Ecuador, la caricatura y el humor gráfico iniciaron con el recuento de Juan Agustín Guerrero a fines del siglo XIX. Desde sus orígenes, la caricatura ecuatoriana tuvo una fuerte orientación política. A medida que los medios impresos ganaban adeptos, la caricatura se fue posicionando como un manifiesto político de carácter periodístico, que, en la medida de lo posible, ha ido madurando y adquiriendo la distancia propia del humorismo.

Los caricaturistas ecuatorianos reconocidos en el panorama nacional son Galo Galecio, quien creó diferentes murales como: Gente de pueblo, Historia del Ecuador y Defensa y protección del trabajador ecuatoriano, y Marcelo Chamorro, quien por medio de sus caricaturas en diario El Comercio criticaba las injusticias sociales. A través de su arte, se expresó la necesidad de rescatar la historia, con el fin de juzgar con más objetividad los acontecimientos más importantes del país. Dada su trascendencia, en Ecuador se instauró el 17 de julio de 2010 como el Día de la Caricatura.

Sin embargo, el devenir del oficio del caricaturista ha sido cuestionado en el debate público ecuatoriano debido a las caricaturas de Xavier Bonilla, alias Bonil, cuyas críticas de humor negro, dirigidas a las autoridades del país, significaron una multa de USD 95000 a diario El Universo, medio al cual se adscribe el caricaturista. Incluso, el expresidente Rafael Correa ordenó a Bonil rectificar una de sus caricaturas. A partir de la trascendencia del humor en el ejercicio periodístico, esta investigación estableció el siguiente problema ¿qué opinan periodistas y caricaturistas orenses sobre el oficio de dibujar caricaturas, de índole político, en el año 2020? Del mismo modo se consideraron las siguientes preguntas complementarias: ¿Debería existir censura para los caricaturistas de temas políticos? ¿La libertad de expresión de la caricatura debe tener límites? ¿Por qué genera controversia la caricatura política? De este modo, los objetivos de la investigación se estructuraron sobre un objetivo general y tres objetivos específicos, los cuales se indican a continuación: a) analizar el ejercicio de la caricatura política orense desde la perspectiva de periodistas y caricaturistas locales, b) reconocer los temas que se abordan en las caricaturas 
políticas locales, c) determinar los motivos de polémica en torno a la caricatura política e d) identificar la función comunicativa que cumple la caricatura política.

En cuanto al contexto de la investigación, cabe mencionar que el presente estudio se ubica geográficamente al sur del país, en la provincia de El Oro, seleccionada por cuanto es un espacio invisibilizado del poder central y caracterizado por una fuerte movilidad humana al situarse en la frontera Ecuador-Perú. La demanda de la investigación social en este territorio era una urgencia por atender, desde la Academia, y dar voz a los periodistas y a los caricaturistas locales en este tipo de análisis fue meritorio para reivindicar la importancia de su trabajo en la línea de comunicación y desarrollo.

\section{Marco teórico}

La caricatura política es un tipo de texto que busca la intensificación de los procesos significativos de descalificación de la política oficial, lo cual es lo propio del discurso político, del discurso polémico. Para ello, despliega una gama de recursos, lingüísticos, retóricos, discursivos y gráficos que crean unos efectos de sentido: unos simulacros que pongan en entredicho los discursos oficiales de las autoridades políticas de un Estado-Nación. Como texto directo y descarnado, ofrece una lectura única y frontal de la realidad donde la caricatura juega un papel de opinión pública sin mensajes ocultos. Es decir, se trata de un texto que no propone una lectura escondida, sino que avanza sobre el sentido en el canal más rápido y directo (Agelvis, 2010).

La caricatura política no es un testimonio de la realidad, sino una construcción de esa realidad. Lo que expresa debe ser leído en esos términos. Sus imágenes atienden asuntos o temas que están en el ambiente y toman elementos de los sucesos y acontecimientos cotidianos para elaborar sus críticas, también subliman, exageran y deforman. En efecto, las caricaturas políticas son vehículos de representación, incluso, instrumentos para actuar sobre la sociedad y condicionar las percepciones individuales y colectivas (Gantús, 2009).

Ibarra (2006) explica que la caricatura política debe analizarse desde dos dimensiones: como una representación gráfica de los problemas que son procesados en la escena política y como una forma de opinión complementaria a la expresión escrita de los medios. A través de su análisis, se promueve una lectura coyuntural sobre el acontecer político y social, relacionada con la mirada del humorista frente a la realidad. Y es que, gracias a la caricatura política, se enfocan los eventos políticos de una manera beligerante. De hecho, las caricaturas son herramientas ideológicas que ayudan a caracterizar el enfoque editorial de cada medio y a utilizar a la imagen como un elemento clave que acentúa los rasgos negativos de los adversarios en segmentos reiterativos. 
Por su parte, Bedoya (2007) considera a la caricatura política como una lectura del caricaturista desde su particular posicionamiento periodístico, cuya interpretación se vincula al momento en que la noticia es producida y se liga al ámbito de lo considerado como político. Este recurso permite entender desde qué lugar se despliega su oficio y qué le está permitido decir o no. La caricatura no solo despliega un texto escrito, sino es el punto de partida desde el cual la ciudadanía comprende las posibilidades móviles del humor visual en un determinado entramado social y las distintas apropiaciones que hacen sus lectores.

La caricatura puede representar una situación a través de su visión de la vida cotidiana. Mediante inversiones y paradojas, permitirse plantear utopías o miradas profundas de los temas esenciales. En efecto, la caricatura no necesita actuar siempre en contra del poder, al contrario, necesita ser crítica e ingeniosa, y estar constantemente cuestionando discursos sólidos. La caricatura es la única que responde de frente al poder de turno y, así, se constituye en un medio idóneo para la protesta y la irreverencia frente al statu quo. El caricaturista necesita pretextos y los gobernantes ayudan a crear la atmósfera oportuna para el humor. En este sentido, la caricatura hace ver cómo se fraguan los procesos de crecimiento del poder y comunica a través de la sátira, lo que coloca al poder en su verdadero sitio. Al apoyarse en su contenido visual metafórico transmite efectivamente su mensaje a la audiencia, de forma clara, contundente, y de fácil recordación. Lo caricaturesco es el símil sobre el país, un lugar donde todo es posible y los únicos que se atreven a mostrar las contradicciones son los caricaturistas (González, Martín, Ruiz-Navarro y Salazar, 2010).

La caricatura se produce como un desacuerdo y no como un símbolo de identificación y conformidad. Su función social consiste en develar una situación, en presentar el lado flaco de un orden establecido; en hallar, dentro de lo solemne, lo ridículo; dentro de lo trascendental, lo vano; dentro de lo serio, lo cómico. La caricatura descubre el oculto talón de Aquiles por donde flaquean los hechos y las gentes. Es el golpe de alfiler que desinfla la bomba del prestigio y es, al mismo tiempo, el benéfico hilo de humor que alivia la tensión de una atmósfera social o política, y que pone a sonreír a las personas al mismo tiempo que les descubre un aspecto insospechado del suceso (Téllez, 1950).

Una caricatura política es muchas cosas a la vez. Llama a la risa, a la crítica, a la reflexión, al movimiento, a la disidencia y hasta a la revolución. La sátira política de la caricatura genera un ambiente adverso de lucha en contra de la hegemonía del poder de turno. En términos estéticos, la caricatura es materialización de la creación artística y, en términos editoriales, es arma y estandarte de luchas políticas y sociales (Acevedo Carmona, 2009). 
Tal y como se analiza, la caricatura política ha cumplido un importante papel en la elaboración y en la apropiación de imaginarios, así como en la construcción de la visión amigo-enemigo de la patria. Como portadora de sentido, tiene un complejo nivel de elaboración simbólica que trasciende la humorada y contribuye a exacerbar los ánimos y el forjamiento de la identidad nacional, sin abandonar la mordacidad y la ironía. Como cualquier representación, la caricatura política coadyuva a la formación de uno mismo y sus relaciones sociales, promueve transformaciones en la cultura y moldea el mundo vivido (Ceballos, 2009).

El espíritu de la actividad humorística se presenta como un desafío a lo relativamente establecido. En este escenario, la caricatura es una poderosa herramienta de expresión de la cultura popular que busca revertir el efecto ideológico de la cultura hegemónica a través de un poder simbólico visual que puede lograr una verdadera transformación en todo orden de cosas (Infante, 2008).

Desde la perspectiva de Peirano y Sánchez (1984), el humor es una forma de conciencia en donde el público suele mirarse y reconocer el ordenamiento social vigente. Los cómicos representan el alma popular y, desde allí, elaboran una resistencia a los modos de vida de la cultura hegemónica.

Autores como Morín (2005) señalan que la caricatura política expone las particularidades de la sociedad, cuya construcción discursiva refleja los imaginarios y la conciencia de la cultura popular, evidencia una concepción determinada del mundo y configura cierto sentido común sobre los problemas políticos.

Las formas de expresarse, entretenerse y divertirse de las culturas populares es el núcleo principal de afirmación de la vida (Peirano y Sánchez, 1984). Por tanto, la caricatura no solo es un instrumento de expresión, sino que refleja una cosmovisión en la cual se almacenan y configuran nuevas significaciones sociales.

Martínez, Peláez Rincón y Trujillo Torres (2008) consideran que la función social de la caricatura es dejar en evidencia el acontecer político a través de la ironía o de la reflexión gráfica. Aquí el humor funciona como una especie de bálsamo que, aunque no resuelve problemas, da otra perspectiva de la realidad y ayuda a que la sociedad se ría de sí misma.

Yánez Hernández (2012) reconoce a la caricatura política como un género hibrido que se vale de una serie de estrategias comunicativas ancladas en sistemas de significación, como la desproporción, y de lenguajes provenien- 
tes de otros fenómenos artísticos, como la pintura, el cine y la fotografía. La caricatura política propaga un mensaje determinado para que sea comprendido con cierta facilidad y presenta a sus lectores temas discutibles de manera simple, concreta y memorable. Además, muestran a los principales actores del drama político como simples mortales, con debilidades humanas y desidealizados.

\section{Metodología}

Esta investigación aplicó una metodología con enfoque cualitativo, por cuanto es un trabajo de naturaleza sociohumanística. Al respecto, se realizaron entrevistas a profundidad a caricaturistas y periodistas ecuatorianos, quienes voluntariamente colaboraron con este estudio, afincado en la provincia El Oro, al sur del Ecuador. Para seleccionar a los participantes se aplicaron los siguientes filtros:

- Periodistas y caricaturistas con mínimo cinco años de experiencia en medios

- Profesionales activos y vinculados a un medio

- Ecuatorianos residentes en el país

Las sesiones individualizadas de entrevistas se realizaron en horario vespertino, de dos horas de duración, entre el 6 y el 31 de enero de 2020, en la ciudad de Machala. La lista de las fuentes de información participante consta en la Tabla 1.

Tabla 1. Fuentes de información entrevistadas

\begin{tabular}{l|l}
\begin{tabular}{l|l} 
Fuentes de información \\
Jorge Moscoso
\end{tabular} & Diario Correo \\
Jéssica Ríos & Diario Correo \\
Bernardo Morales & Diario El Nacional \\
Fernando Castilla & Diario El Nacional \\
Xavier Bonilla & Diario El Universo \\
Jorge Prócel & Semanario La Verdad \\
Kléber Aguilar & K-Noticias
\end{tabular}

Las sesiones de entrevistas se direccionaron como un diálogo abierto, no estructurado, a fin de dar libertad a los participantes de exponer el tema, sin 
restricciones de formato. Posteriormente, el procesamiento de las respuestas se categorizó en la matriz referenciada por Valdivia (2017) (ver Tabla 2).

Tabla 2. Matriz de análisis de entrevistas

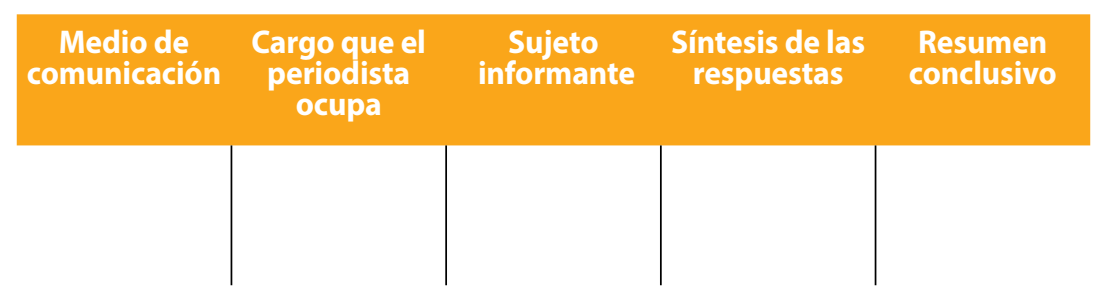

Fuente: Valdivia (2017)

\section{Resultados}

Al término del trabajo de campo se sistematizó la información obtenida por parte de los sujetos participantes y se detectaron nueve puntos recurrentes en los diálogos sostenidos con los entrevistados. Estos fueron:

- Caracterización de la caricatura política ecuatoriana

- Temas abordados en la caricatura política ecuatoriana

- Libertad de expresión y caricatura

- Censura en la caricatura

- Caricatura y derechos humanos

- Controversia y polémica de la caricatura política

- Verdades y falacias en la caricatura política

- Enfrentamiento y disputas con el gobierno de turno

- Mejoras en el oficio del caricaturista

A continuación, se desglosa la interpretación de cada uno de estos puntos de análisis en la voz de los entrevistados.

\subsection{Caracterización de la caricatura política ecuatoriana}

A criterio de los entrevistados, la caricatura política es un dibujo de fuertes distorsiones y exageraciones, con el fin de demostrar humorísticamente una opinión, un mensaje y una información específica acerca de temas coyunturales de un Estado-Nación. Lo consideran un recurso eficaz para expresar la parte cómica de una noticia y, en ocasiones, exagera el contenido de esta con el propósito de provocar burla hacia el personaje que se está dibujando. Los entrevistados comentan que ciertas figuras políticas actúan de manera cínica, lo que causa risa, preocupación, incluso ira ante la mirada y el escrutinio público. 
Los entrevistados conciben a la caricatura política como un género periodístico de opinión pública que simboliza la parte graciosa de la política nacional. La mayoría de sus retratados son políticos de alto rango (alcaldes, prefectos, asambleístas orenses, jefe político), ya que estas figuras están expuestas a la mira de los medios de comunicación las 24 horas, todos los movimientos que ellos hagan serán noticia. En este punto, los entrevistados afirman que sus caricaturas son una poderosa arma de lucha contra los políticos corruptos, de hecho, comentan que las fuertes críticas y burlas simbolizadas en sus caricaturas provocan decepción y desprecio de parte de la sociedad hacia los personajes que son dibujados.

Mencionan, además, que el objetivo de la caricatura política es causar risa en torno a las personalidades del medio político debido a las decisiones arbitrarias que toman, sin previa consulta popular. Se inspiran en las actividades que estos realizan y sus intervenciones públicas, todo ello es motivo de sátira e ironía. Según refieren, existe una función social en el ejercicio de dibujar caricaturas y se basa en cuestionar las decisiones de los políticos e instar a la sociedad a analizar los actos públicos y pedir rendición de cuentas a los gobernantes. Los entrevistados mencionan que el propósito último de la caricatura es motivar el escrutinio de cada una de las acciones ejercidas por los funcionarios de gobierno y develar a la ciudadanía actos políticos ambiguos que merecen transparencia.

\subsection{Temas recurrentes de la caricatura política ecuatoriana}

Los entrevistados coinciden en que la mayoría de temas que inspiran sus caricaturas son los actos de corrupción por parte de los funcionarios públicos del gobierno local. Para elegir un tema en específico, seleccionan la noticia con mayor relevancia social y cuya caricatura impacte en el lector. Jorge Moscoso, caricaturista de diario Correo, explica que, para dibujar una caricatura, el medio les exige estar informados de las últimas noticias en múltiples plataformas (televisión, radio, prensa e Internet) pues la caricatura se realiza de un tema noticioso que busca entretener con humor. Por su parte Prócel, caricaturista de semanario La Verdad, manifiesta que todo es caricaturizable y depende del ingenio del caricaturista determinar sobre qué noticia pone el foco de atención. De forma adicional, Bernardo Morales, caricaturista de diario El Nacional, opina que el medio le pide caricaturizar temas de política local y de la comunidad. Para ello, él está pendiente de las actividades de los alcaldes, sus discursos y la agenda de medios que cumplan, mientras que Jéssica Ríos, de diario Correo, reconoce que el espectro es amplio, se puede hablar de muchísimos temas. En su caso, han recurrido a caricaturas con el fin de recrear hechos de la crónica roja y de la política nacional, mediante el recurso de la ironía y sátira, sin caer en lo ofensivo o vulgar. 


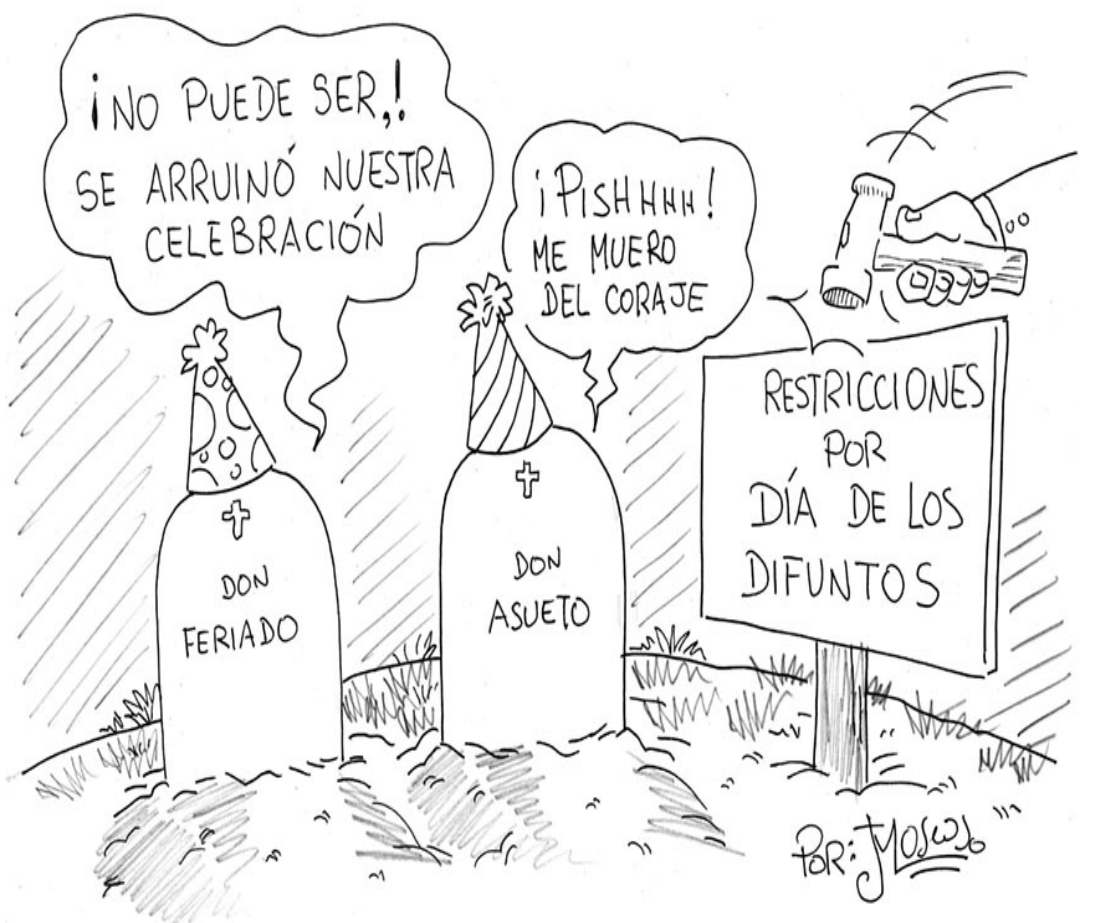

Caricatura del diario Correo de la provincia de El Oro, del caricaturista Jorge Moscoso.

\subsection{Libertad de expresión y caricatura}

Sobre este tema, Jorge Moscoso, de diario Correo, afirma que los caricaturistas no pueden caer en especulaciones. Prócel, caricaturista de semanario La Verdad, comenta lo siguiente:

La caricatura es permitida hasta donde le gobierne la conciencia al artista puesto que hay que respetar al prójimo, la honra ajena, valiosa como la honra de uno mismo. Las leyes no pueden regular a los caricaturistas. Por ejemplo, si un caricaturista hace un dibujo de alguien, sin poner nombres, y el ofendido denuncia legalmente al dibujante, este se va a defender con la base de que si se hubiese referido a alguien hubiera puesto nombres, y entonces el juez desecha la demanda, pero nadie reparara el daño moral que ha causado a la víctima. Por tanto, el único límite que tiene el caricaturista y el periodista es su propia moral, su propia ética, sus propios valores, él de respetar la dignidad de los demás. (comunicación personal, 6 de enero de 2020) 


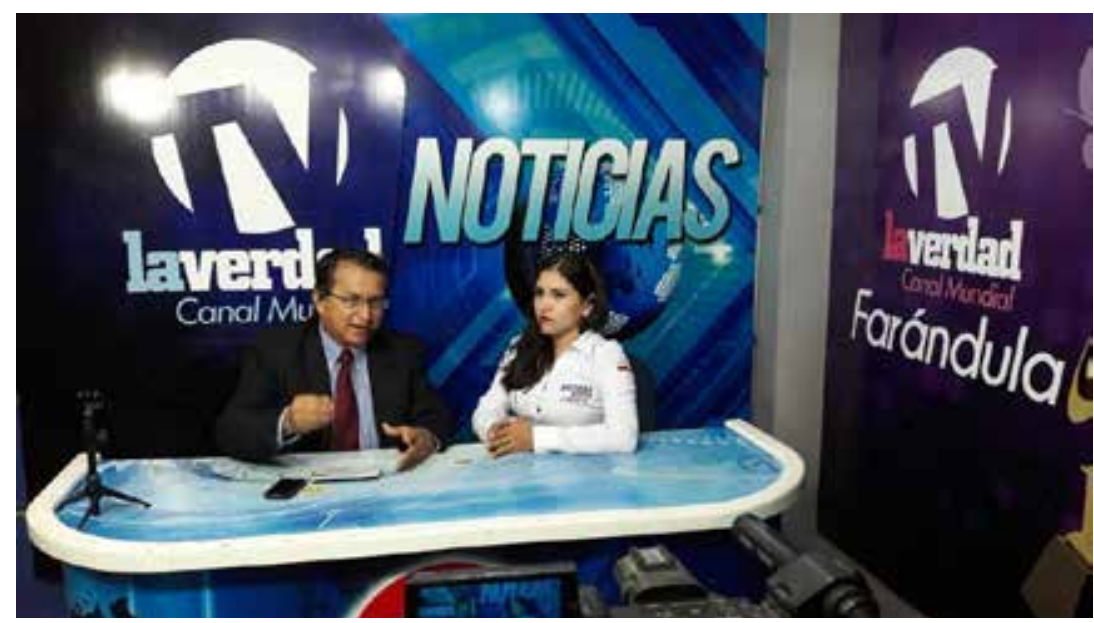

Jorge Prócel es periodista del semanario La Verdad, que en la actualidad, consolida radio, televisión y prensa en un solo portal digital. Crédito: semanario La Verdad.

Este mismo criterio comparte Jéssica Ríos, de diario Correo, quien menciona que:

el límite que debe existir es el límite del respeto hacia los demás. La caricatura no puede ser un instrumento de insulto o de acusación de un delito sin tener pruebas. No puedo hacer de eso una herramienta para ofender. La libertad de expresión conlleva una limitación ética del dibujante y de quien la publica. (comunicación personal, 7 de enero de 2020)

En esta misma línea, Kléber Aguilar, de K-Noticias, afirma que en la libertad de expresión de un caricaturista tienen que primar los derechos de los demás. Añade:

No podemos excedernos más allá de los límites de nuestros derechos. La libertad de expresión, como la palabra lo indica, significa expresar todo lo que debemos decir sin soslayar al otro. ¡Mi derecho termina donde empieza el derecho de las otras personas! Es una máxima que debemos siempre aplicar. (comunicación personal, 8 de enero de 2020)

Sin embargo, no todos opinan de forma consensuada. Bernardo Morales, de diario El Nacional, cree que no deben existir límites para la libertad de expresión, siempre y cuando lo que se dibuje sea veraz y eficaz, igual juicio de valor comparte Xavier Bonilla, de diario El Universo, quien advierte que los límites no se aplican en el arte y explica: "Yo como caricaturista no puedo ponerme a pensar en límites, sino en mis expresiones, en mi libertad como artista" (comunicación personal, 9 de enero de 2020). 


\subsection{Censura en la caricatura}

Bernardo Morales, de diario El Nacional, opina que todavía existe censura para los caricaturistas, la cual no está constitucionalizada, pero es permeable al terrero de la comunicación. “Para el gran censor de la mafia, como lo es el mundo de la política, no se puede reír de algo porque es políticamente incorrecto. Esos son los sensores que creen que pueden cerrarle la boca al caricaturista", añade Bonil, de diario El Universo (comunicación personal, 9 de enero de 2020). En palabras de Fernando Castilla, de diario El Nacional, "los medios son un negocio, una empresa que tiene accionistas, quienes influyen en la censura de una determinada caricatura, incongruente con la línea editorial y los intereses del diario" (comunicación personal, 10 de enero de 2020).

Jorge Moscoso, de diario Correo, refiere que actualmente ya no ocurre la censura, como en gobiernos anteriores. Comenta: "Durante la presidencia de Rafael Correa, a través de la Superintendencia de Comunicación, los caricaturistas estábamos bastante censurados" (comunicación personal, 11 de enero de 2020). De igual manera, Jéssica Ríos, de diario Correo, manifiesta que la censura, como tal, no aplica. Declara: “Una cosa es censura y otra cosa es no permitir que salga una caricatura ofensiva" (comunicación personal, 7 de enero de 2020).

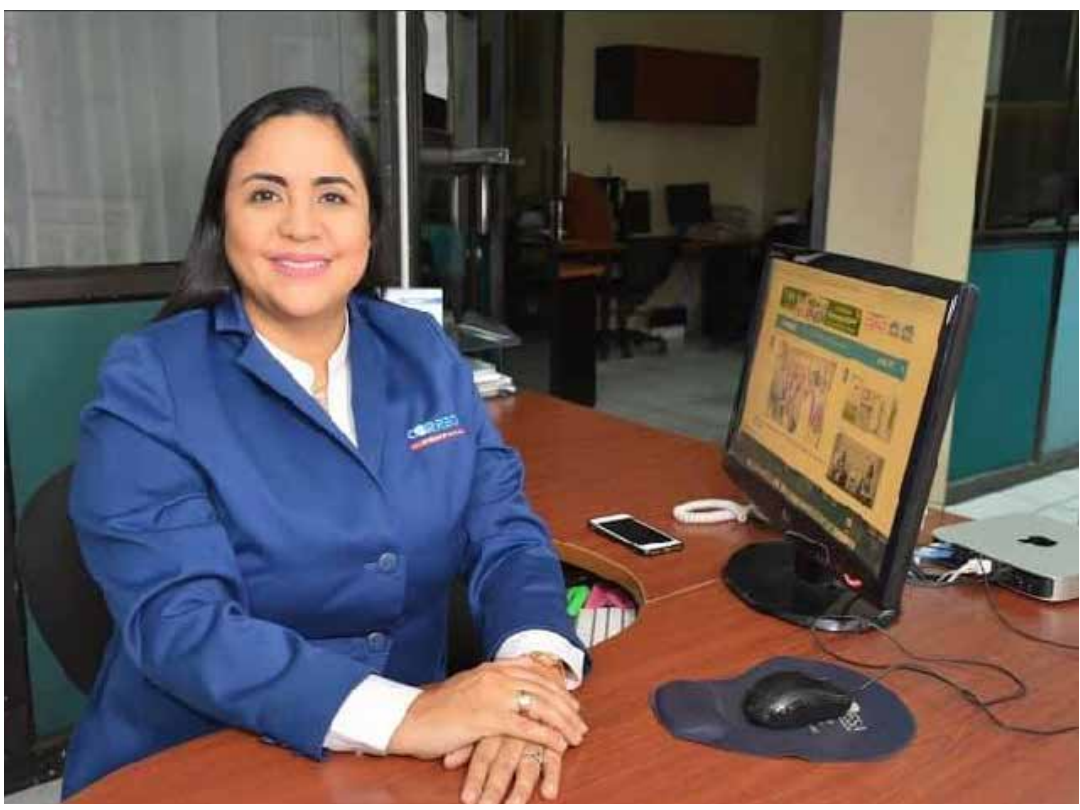

Jéssica Ríos es periodista de diario Correo, con sede en Machala, capital de la provincia de El Oro. Crédito: diario Correo. 


\subsection{Caricatura y derechos humanos}

Según el criterio de algunos entrevistados, dibujar caricaturas es permitido siempre y cuando no perjudique la honra de las personas, ni viole algún derecho humano. Si bien el propósito de la caricatura es mostrar, de forma graciosa, lo que ocurre en la sociedad, existen caricaturas extremadamente exageradas que se convierten en piezas gráficas vulgares. Entonces, si las caricaturas sobrepasan el aspecto cómico y se convierten en ordinarias, no solo afectará a la persona que es dibujada, sino que el público también percibirá mal estos dibujos y este hecho puede ser perjudicial para el propio caricaturista.

"Algunas veces sí se hacen caricaturas que vulneran los derechos humanos, esto es un tema moral que el caricaturista tendrá que responder a su conciencia", opina Fernando Castilla, de diario El Nacional (comunicación personal, 10 de enero de 2020). Por su parte, Jorge Moscoso, de diario Correo, advierte que "la caricatura tiene que dibujarse con el suficiente conocimiento del tema qué se está abordando, caso contrario, podemos ocasionar algún daño por expresar algo que no es verdad" (comunicación personal, 11 de enero de 2020). Igual criterio tiene Jéssica Ríos, de diario Correo, para quien una caricatura que ofende a otra persona atenta contra sus derechos humanos. Explica: "Todos quienes trabajamos en medios de comunicación tenemos la obligación de respetar los derechos humanos, los derechos civiles, los derechos constitucionales, la honra al buen nombre" (comunicación personal, 7 de enero de 2020).

Pero no todos opinan así, Bernardo Morales, de diario El Nacional, detalla que "la caricatura no vulnera los derechos humanos, más bien con nuestros dibujos mostramos pelea porque se respeten esos derechos" (comunicación personal, 12 de enero de 2020). De forma paralela, Prócel, de semanario La Verdad, argumenta que el problema radica en la lectura literal de la caricatura. Añade:

Para hacer caricaturas se requiere un mínimo de inteligencia, de mucho sarcasmo. La ironía es una especie de metalenguaje que comunica más allá de lo que está escrito o dibujado. Poder utilizar este tipo de lenguaje requiere de lectores con una posición crítica, con otra manera de ver el mundo. Por eso se tilda a la caricatura de conflictiva y que vulnera derechos, pues su mensaje no se interpreta a profundidad. (comunicación personal, 6 de enero de 2020)

\subsection{Controversia y polémica de la caricatura política}

Desde la postura de ciertos entrevistados, como Jorge Moscoso:

La caricatura política tiene que ser controversial, allí radica su éxito: dar de qué hablar, generar distintos puntos de vista. Por ejemplo, si realizo una 
caricatura sobre los juicios del ex presidente Rafael Correa, habrá seguidores políticos que no aceptarán mi caricatura y es ahí cuando aparece la controversia. Insisto, eso es bueno, de eso se trata la caricatura, de provocar reacciones, diversas opiniones, crear un debate social. (comunicación personal, 11 de enero de 2020)

Por su parte, Xavier Bonilla, de diario El Universo, afirma que: "la caricatura irrumpe con la risa y con la ridiculización de un personaje político lo cual es controversial para el poder, puesto que constituye una venganza simbólica contra los corruptos, los abusivos y los imponentes" (comunicación personal, 9 de enero de 2020).

En este sentido, Fernando Castilla, de diario El Nacional, coincide al argumentar que "la política de por sí es controversial ya que en la sociedad cada uno piensa diferente y eso se aplica con los caricaturistas, quienes buscan debatir con su arte, hacer revolución a través del humor" (comunicación personal, 10 de enero de 2020). Para Kléber Aguilar, de K-Noticias, "no solo en Ecuador la caricatura política es controversial, a nivel mundial también lo es, pero eso está bien, porque debe primar la diferencia, la variedad de opiniones con un valor agregado como es el arte" (comunicación personal, 08 de enero de 2020).

Criterio aparte es el de Jéssica Ríos, de diario Correo, para quien la caricatura no es controversial por naturaleza, sino que la controversia la crean las personas. Afirma:

La controversia va a darse de parte de alguien que se sienta aludido, afectado por la caricatura. Entonces, este arte no es controversial en esencia, más bien es un recurso muy válido que promueve el análisis de los hechos, en un plano de cultura popular. (comunicación personal, 7 de enero de 2020)

\subsection{Verdades y falacias en la caricatura política}

Los entrevistados reconocen que la caricatura es un híbrido entre verdad y supuestos. "Pienso que la caricatura exagera y dice la verdad al mismo tiempo, es algo de ambas", comenta Jorge Moscoso, de diario Correo (comunicación personal, 11 de enero de 2020), mientras que, para Bernardo Morales de diario El Nacional, "la caricatura, a través de sus exageraciones, quiere mostrar algo que no ha enseñado antes los medios de comunicación y es que a través de la deformación de sus personajes comunica verdades políticas" (comunicación personal, 12 de enero de 2020). Fernando Castilla, de diario El Nacional, expresa que: "la habilidad de un caricaturista es decir la verdad de una manera disfrazada, que tenga algo de comicidad, con mensajes políticos potentes" (comunicación personal, 10 de enero de 2020). En palabras de Kléber Aguilar de K-Noticias, "siempre hay exageraciones en las caricaturas, pero eso no sig- 
nifica que no comunique los hechos" (comunicación personal, 8 de enero de 2020). Por su parte Jéssica Ríos afirma que "la caricatura política ecuatoriana maneja un humor muy fino, apegado a la realidad" (comunicación personal, 8 de enero de 2020).

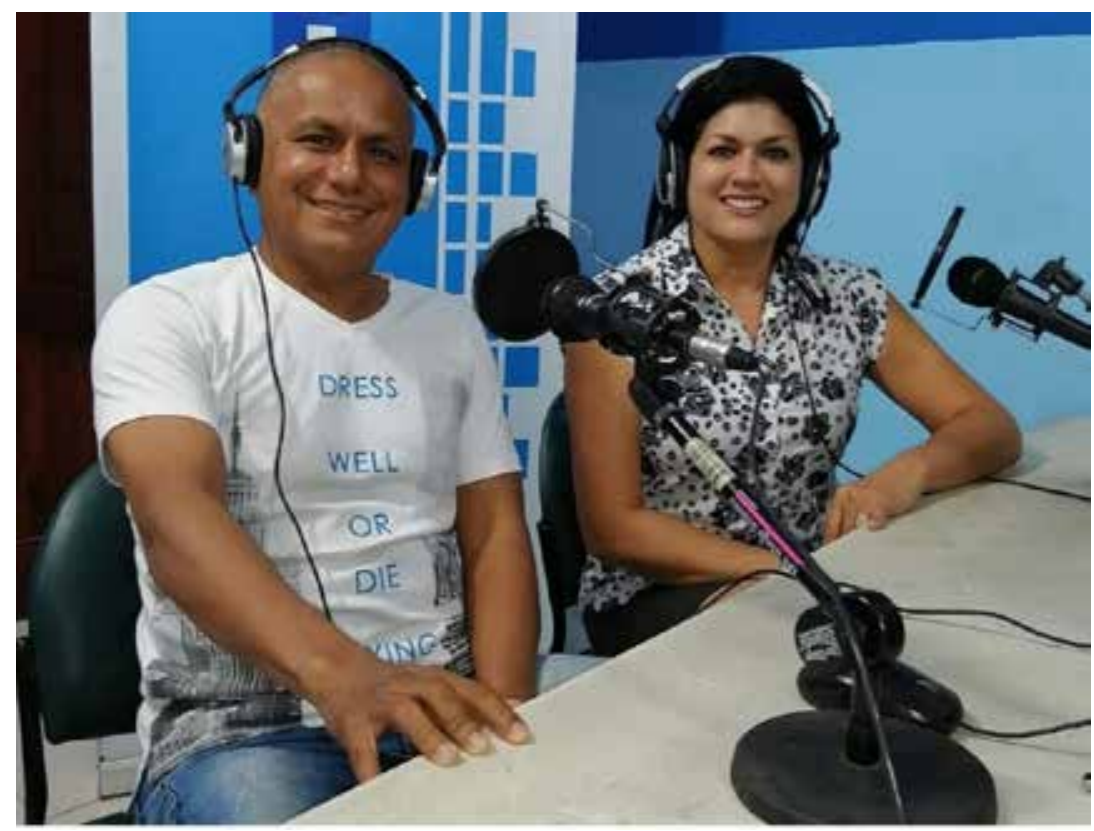

Kléber Aguilar es vicepresidente del Colegio de Periodistas de El Oro y director del medio K-Noticias. Colegio de Periodistas de El Oro.

\subsection{Enfrentamiento y disputas con el gobierno de turno}

Para los periodistas entrevistados, antes, con el gobierno del expresidente Rafael Correa, existía bastante represión contra los caricaturistas, evitando que hablen de la política nacional en comparación con la época actual, donde, a su juicio de valor, los periodistas sienten más libertad de publicar caricaturas. En su testimonio revelan sentirse más seguros a la hora de publicar caricaturas ya que la Cordicom ha dejado de ser un ente represor de los periodistas ecuatorianos. Según explica Kléber Aguilar, de K-Noticias:

en la época del exmandatario Rafael Correa las demandas contra el caricaturista Bonil fueron exageradas, se hizo un tema personal. Es más, cuando sufrió estas demandas, Bonil fue premiado a nivel mundial, lo que significa que la gente estaba de acuerdo en que defendía el derecho a expresarse y a comunicarse por todos los medios. (comunicación personal, 8 de enero de 2020) 
A criterio de los entrevistados, los gobiernos de turno deben crear condiciones para que los caricaturistas se expresen sin miedo a la represión. Jéssica Ríos, de diario Correo, comenta que:

en las demandas del gobierno contra los caricaturistas, como en el caso de Bonil, salen airosos los artistas y lo toman con un poco de humor, que es como debe ser, no de una mala manera. Ellos se defienden desde el humor y eso vale mucho más para el público. (comunicación personal, 7 de enero de 2020)

Desde la perspectiva de Fernando Castilla, de diario El Nacional,

hay algunas demandas que son motivadas por revanchas políticas, pero bien dicen que, si uno se mete para soldado, no esperes a que te lancen flores, sí uno usa armas, se va a enfrentar a gente con armas, uno vive según las normas que se pone. Dicen que la controversia es adrenalina, pero en este caso la controversia contra los caricaturistas políticos parece nunca llegar a un fin. Rafael Correa ya terminó su mandato hace cuatro años y sigue la controversia y seguirá. (comunicación personal, 10 de enero de 2020)

Jorge Moscoso, de diario Correo, cree que el caso de Bonil sirvió para callar a muchos caricaturistas.

Bonil fue uno de las personas perseguidas y condenadas por el gobierno de Correa, por el simple hecho de publicar algo que no le gustaba al ex mandatario. Al ver estas situaciones, los caricaturistas locales tenemos bastante cuidado de lo que dibujamos, revisamos una y otra vez, para estar seguros de que nada de lo que se difunda ocasione algún problema con el gobierno. (comunicación personal, 11 de enero de 2020)

En palabras de Bonil de diario El Universo, "yo soy responsable de lo que dibujo y tú de lo que interpretas" (comunicación personal, 9 de enero de 2020). En este punto, añade Bernardo Morales, de diario El Nacional, "las confrontaciones del gobierno y los caricaturistas han constituido fuertes peleas" (comunicación personal, 12 de enero de 2020). En ese escenario, los artistas orenses luchan por publicar libremente sus dibujos, pero entonces sigue la polémica desde el poder de turno, fruto de la intolerancia.

\subsection{Mejoras en el oficio del caricaturista}

Kléber Aguilar de K-Noticias recomienda a los caricaturistas orenses asistir a centros de formación y prepararse internacionalmente para adquirir nuevas técnicas y así llegar de una mejor manera a la comunidad. "La caricatura le da un color a la comunicación, ese color vistoso hacer ver diferente a los medios, 
y por tanto los directivos de los diarios deben apostar por preparar a su talento humano", refiere (comunicación personal, 8 de enero de 2020). Para Jéssica Ríos, el caricaturista debe hacer trabajo de campo a fin de

empaparse un poco más de los problemas de la localidad. Si hay investigación de fondo, la caricatura no se tomará a la ligera. Es un arte complejo de un breve texto, de unas cuantas palabras, pero esas palabras tienen que ser las precisas, tienen que recoger el sentimiento popular, el sentir del ciudadano y que este logre identificarse. Por ello, con un poco de preparación en cuanto al contexto noticioso el caricaturista logrará plasmar su arte con calidad y excelencia. (comunicación personal, 7 de enero de 2020)

A criterio de Prócel de semanario La Verdad,

el caricaturista realiza un trabajo intelectual. Entonces hay que ser creativo, desarrollar un poco la inteligencia mediante el ejercicio asiduo de la lectura, eso va ayudarle muchísimo. Generalmente hay muy poca creatividad, las caricaturas son prácticamente por encargo, incluso en los pequeños textos de las caricaturas aparecen faltas ortográficas. (comunicación personal, 6 de enero de 2020)

Por su parte, Fernando Castilla de diario El Nacional considera que la caricatura mejoraría si se enfoca desde un punto de vista constructivo. De igual forma coincide Bernardo Morales, quien destaca que "estos dibujos podrían ayudar siempre y cuando influyan a algo positivo, fomenten soluciones y reflejen noticias beneficiosas para la sociedad" (comunicación personal, 10 de enero de 2020).

\section{Discusiones}

La propuesta de esta investigación focalizada geográficamente en la provincia de El Oro es inédita y está en congruencia con los estudios planteados por González et al. (2010), quien reunió un panel de cinco caricaturistas para analizar el recorrido histórico de este arte en Colombia. De igual manera, Guadarrama Rico (2017) propuso el análisis de una reforma del poder ejecutivo del gobierno de México y, para ello, congregó a cinco caricaturistas en una mesa de debate. En esta misma línea, Martínez et al. (2008) dialogaron sobre la caricatura aplicando la técnica de la entrevista a profundidad a los protagonistas de este oficio.

En cuanto a los puntos comunes que resultaron de las entrevistas con los caricaturistas orenses (libertad de expresión, censura, derechos humanos, falacias, disputas con el gobierno) se sitúan investigaciones análogas que rescatan estas mismas preocupaciones. Así tenemos la investigación de Flores Borjabad 
(2019a), quien analizó el rol de la caricatura activista y su importancia para la libertad de expresión. El trabajo de Rodas Coloma (2017) vinculó el humor de la caricatura política como una forma de resistencia al poder. Del mismo modo, el tema de la vulneración de los derechos humanos en la caricatura es motivo de análisis para García Torres y Punín (2017), quienes tomaron como estudio de caso la viñeta pobretín/pobretín pobretón/pobretón de Xavier Bonilla.

Una investigación clave para comprender la censura a los caricaturistas políticos es el estudio de Teitelbaum (2011), quien analizó el devenir de este oficio en ciudad de México, cuyo arte fue motivo de censura y represión durante 1876-1888. Quero (2015) también investigó el tema de la censura a caricaturistas venezolanos en su estudio titulado Caricaturistas: Aguafiestas bajo riesgo. Según este autor, el poder debe acostumbrarse a la crudeza de la caricatura política porque el humor es parte de la esencia de la sociedad.

Mientras que Yupanqui (2008) explora los alcances del humor dentro de la sociología de la cultura y su relación con el poder. En este sentido, Rodríguez Camargo y Velasco Orjuela (2011) investigan sobre el discurso multimodal en la caricatura internacional del periódico The Washington Post y concluyen que el corte humorístico-satírico de la caricatura evidencia los discursos ridiculizantes de los políticos de turno. Por otra parte, Acevedo Carmona (2003) formuló una serie de reflexiones teóricas sobre el valor de la caricatura para la formación de imaginarios políticos. Finalmente, el tema de las falacias es retomado por Flores Borjabad (2019b), quien denomina a la caricatura política como una caricatura de la posverdad, que habla de verdades profundas a través de la ficción (Alatriste, 2010), es una especie de elogio de la mentira (Cabrero, 2006) que remite a falsas verdades (Duque, 2002).

\section{Conclusiones}

El planteamiento novedoso sobre el estudio de la caricatura es que los caricaturistas entrevistados de la provincia de El Oro, a diferencia de caricaturistas afiliados a los grandes medios de comunicación de alcance nacional, no tienen una formación académica. De hecho, no cuentan con un título de tercer nivel. Sin embargo, aunque ejercen su oficio de forma empírica reconocen que el humor debe ser permitido siempre y cuando respete la honra ajena y, en particular, la opinión de las personas. No fomentan un humor absurdo y abusivo. Los caricaturistas entrevistados tienen presente que los límites son autoimpuestos por la conciencia de quien dibuja. Consideran que la honra ajena es valiosa como la honra de uno mismo y el único límite que tienen es su propia moral, su ética y sus valores. Enfatizan en que un buen caricaturista tiene la habilidad de crear humor sin soslayar el principio de respeto hacia la dignidad de los demás. 
Para los caricaturistas orenses, los temas abordados en sus caricaturas tienen relación con noticias cantonales, de proximidad geográfica, protagonizado por autoridades locales. Sus dibujos critican las malas decisiones de los mandatarios y cuestionan las malversaciones de los fondos públicos. Los entrevistados manifestaron que el éxito de una buena caricatura radica en generar reacciones, crear un debate en la sociedad. A su criterio, la ridiculización de un personaje es una especie de venganza simbólica contra los corruptos, los abusivos y los imponentes.

La función comunicativa que cumple la caricatura orense es la denuncia social, de crítica al sistema, esa es la esencia del mensaje que se transmite y para lograrlo se apela a la exageración en el trazado del dibujo. Se inspiran en un tema de coyuntura y la recrean a partir de una visión personal, subjetiva, simbolizada en diálogos cortos, con ironía y frases coloquiales.

Gracias a la naturaleza mordaz y oscura de la caricatura, el lector activa mecanismos de análisis en torno a realidades políticas y se cuestionan los pseudovalores que la sociedad actual ha normalizado. En este punto, Tusa, Fontaines-Ruiz y Briceño Castillo (2017) argumentan que el humor se aproxima a un discurso alterativo de todo orden social, que apela a los antivalores del mundo para, desde allí, cuestionarlos. Por tanto, constituye un material privilegiado para la búsqueda desnuda de aquellos modos de producción social que imperan en el mundo occidental. Lo beneficioso de la caricatura política es que promueve, en las personas, el espíritu de discutir importantes temáticas que marcan la cultura ciudadana. Este humor, puesto en clave de caricatura, nos ayuda a reconocer los valores en los que realmente creemos, detecta estereotipos, critica los vicios de la sociedad y trata de mejorar éticamente la vida del ser humano (Siurana, 2013). 


\section{Referencias}

Acevedo Carmona, D. (2003). La caricatura editorial como fuente para la investigación de la historia de los imaginarios políticos: reflexiones metodológicas. Historia y sociedad, (9), 151-173.

Acevedo Carmona, D. (2009). Política y caudillos colombianos en la caricatura editorial, 1920-1950. Medellín: La Carreta Editores.

Agelvis, V. (2010). Zapata y la caricatura. Anuario Grhial, (4), 43-62.

Alatriste, S. (2010). Verdades profundas a través de la ficción. Revista de la Universidad de México, (81), 5-15.

Ayala, F. (2010). La caricatura política en el Porfiriato. Revista Estudios Políticos, 9 (21), 63-82.

Bedoya, M. E. (2007). Trazos del tiempo: la caricatura política en el Ecuador a mediados del siglo XX. Ecuador Debate, (71), 185-186.

Cabrero, M. C. (2006). Elogio de la mentira. Bahía Blanca: EdiUNS-Universidad Nacional del Sur.

Ceballos, D. (2009). Reseña del libro Política y caudillos colombianos en la caricatura editorial, 1920-1950. Historia y Sociedad, (17), 237-282.

Duque, A. A. (2002). Las falsas verdades. Manizales: Universidad de Caldas.

Flores Borjabad, S. A. (2019a). Ali Ferzat: De la caricatura comunicativa en papel a la caricatura activista en los medios digitales. Ámbitos. Revista Internacional de Comunicación, (46), 108-132. doi: 0.12795/Ambitos.2019.i46.0

Flores Borjabad, S. A. (2019b). Comunicación en imágenes en las sociedades árabes: la caricatura y su posverdad. Ámbitos. Revista Internacional de Comunicación, (45), 182-202. doi: 10.12795/Ambitos.2019.i45.11

Gantús, F. (2009). Caricatura y poder político. Crítica, censura y represión en la ciudad de México, 1876-1888. México D.F.: El Colegio de México, Instituto de Investigaciones Dr. José María Luis Mora.

García Torres, C., y Punín, M. (2017). Opinión y discriminación. Humor político en Ecuador y el caso Tín Delgado. Question/Cuestión, 1(55), 258-274. Recuperado de https://www.perio.unlp.edu.ar/ojs/index.php/question/ article/view/4266 
González, J., Martín, A., Ruiz-Navarro, C., y Salazar, C. (2010). Sobre la caricatura. Revista De Estudios Sociales, (35), 139-146. doi: 10.7440/res35.2010.12

Guadarrama Rico, L. (2017). Reforma Energética en México. La humorística desde la mirada de cinco caricaturistas del periódico La Jornada. La Laguna: Universidad de La Laguna.

Ibarra, H. (2006). Trazos del tiempo. La caricatura política en el Ecuador a mediados del siglo XX. Quito: Museo de la Ciudad.

Infante, C. (2008). Poder, tensión y caricatura. Una aproximación a la teoría del humor. Dialogía, (3), 245-271.

Martínez, A., Peláez Rincón, J. y Trujillo Torres, H. (2008). Los caricaturistas opinan sobre caricatura. Revista de Estudios Sociales, (30), 82-85.

Morín, E. (2005). Cómic y ciudad. Un tributo a los Burrón. En A. Vergara Figueroa (Ed.), Antropologías y estudios de la ciudad, (pp. 48-56). México: Conaculta- INAH.

Peirano, L. y Sánchez, A. (1984): Risa y cultura en la televisión peruana. Lima: Desco.

Quero, H. J. (2015). Caricaturistas: aguafiestas bajo riesgo. Comunicación: estudios venezolanos de comunicación, (169), 51-59.

Reniz Caballero, D. (2013). Caricatura, humor y derecho a la honra. Signo y Pensamiento, 12(23), 123-126.

Rodas Coloma, F. A. (2017). Caricatura política y el humor como resistencia al poder. Caso 30 de septiembre de 2010 (Tesis de maestría, Universidad Andina Simón Bolívar, Sede Ecuador).

Rodríguez Camargo, D. P. y Velasco Orjuela, A. M. (2011). Análisis crítico del discurso multimodal en la caricatura internacional del periódico The Washington Post. Cuadernos de Lingüística hispánica,(17), 39-52.

Siurana, J. (2013). Los rasgos de la ética del humor. Una propuesta a partir de autores contemporáneos. Revista Veritas, (29), 9-31. doi: 10.4067/S071892732013000200001

Teitelbaum, V. (2011). Caricatura y poder político. Crítica, censura y represión en la ciudad de México, 1876-1888. Secuencia, (81), 193-197. 
Téllez, H. (1950). El caricaturista Adolfo Samper. Revista Semana, (204).

Tusa, F., Fontaines-Ruiz, T. y Briceño Castillo, X. (2017). El género negro dentro del humor. Revista Chilena de Literatura, (95), 203-229.

Valdivia, M. (2017). Matriz de Consistencia Categorial de las Entrevistas Cualitativas. Blog de educación. [Tabla]. Recuperado de https://cutt.ly/bwd$\mathrm{mm} 4 \mathrm{H}$

Yánez Hernández, A. (2012). Un acercamiento a la caricatura. Algunas consideraciones semiósicas. Visitas al patio, (6), 131-150.

Yupanqui, C. I. (2008). Poder, tensión y caricatura. Una aproximación a la teoría del humor. Dialogía,(3), 245-271. 